Check for updates

Cite this: RSC Adv., 2021, 11, 565

Received 21st September 2020 Accepted 22nd November 2020

DOI: $10.1039 / \mathrm{dOra08058f}$

rsc.li/rsc-advances

\section{Nanoporous fluorescent sensor based on upconversion nanoparticles for the detection of dichloromethane with high sensitivity $\dagger$}

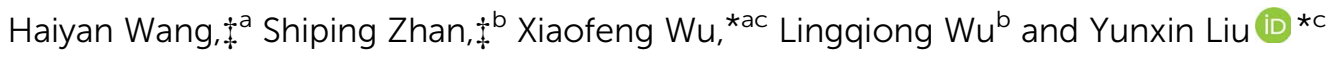

A sensor with high sensitivity and response rate is still lacking in the detection of poisonous and volatile chemicals. Here, we report a highly sensitive nanoporous fluorescence sensor based on coreashell upconversion nanoparticles (UCNPs) for the detection of dichloromethane. UCNPs were deposited on porous anodic alumina oxide (AAO) templates supported by glass slides to form a thin film-like gas sensor in which UCNPs with active shells exhibit intense background-free fluorescence and simultaneously high optical sensitivity, while an AAO template acts as a porous substrate for UCNPS to increase the absorption capacity for molecules to be tested. A detection limit of $2.91 \mathrm{ppm}$ was obtained for dichloromethane based on this sensor at room temperature. The involved response mechanism was attributed to lowered surface fluorescence quenching and scattering of UCNPs by dichloromethane.
\end{abstract}

\section{Introduction}

As one of the most powerful luminescent nanocrystals, upconversion nanoparticles (UCNPs) have received extensive attention owing to their advantages of multicolor, narrow bandwidth, and no photobleaching, ${ }^{1}$ due to which they have been extensively applied for background-free imaging, biological detection labeling, ${ }^{2,3}$ temperature sensing, ${ }^{4}$ and solar cells with enhanced infrared absorption. ${ }^{5}$ They have been confirmed to be very efficient in the detection of glutathione, ${ }^{6}$ DNA, ${ }^{7}$ disease biomarkers, ${ }^{8}$ metal ions, ${ }^{9-11}$ and dyes. ${ }^{12}$ Recently, this specific material is reported to be sensitive to $\mathrm{NH}_{3}, \mathrm{CO}, \mathrm{NO}$, and $\mathrm{H}_{2} \mathrm{~S} .{ }^{13-16}$ However, traditional UCNPs suffer tremendous fluorescence quenching problem, which seriously limits their further application in the highly sensitive detection of volatile organic compounds.

Volatile organic compounds (VOC) such as dichloromethane, which are widely used in the pharmaceutical industry and in the production of cine-films, are harmful to the environment and cause human liver and nervous system injury or even cause cancer. ${ }^{17-20}$ As per the safety standards for occupational exposure to dichloromethane (DCM), the concentration

\footnotetext{
${ }^{a}$ Department of Information and Electrical Engineering, Hunan University of Science and Technology, Xiangtan 411201, China

${ }^{b}$ Department of Physics and Electronic Science, Hunan University of Science and Technology, Xiangtan 411201, China

'School of Computer and Information Engineering, Hunan University of Technology and Business, Changsha 410205, China. E-mail: lyunxin@163.com; xfwuvip@126. com

$\dagger$ Electronic supplementary information (ESI) available. See DOI: 10.1039/d0ra08058f

\$ These authors are joint first authors and contributed equally to this work.
}

of DCM at TWA-75 ppm and a ceiling of 500 ppm was recommended using related functional departments. ${ }^{21}$ Therefore, the precise detection of DCM is very desirable and important in the related industries. Currently, DCM gas sensors based on semiconductors, ${ }^{22-25}$ carbon nanotubes, and polymers ${ }^{26,27}$ have been reported. Lee et al. reported a $\mathrm{SnO}_{2}$-based gas sensor for DCM measurement that possessed high sensitivity (ppm level) but suffered from ultrahigh operation temperature $\left(350{ }^{\circ} \mathrm{C}\right) . .^{22,23}$ Winadda et al. proposed a DCM sensor based on carbon nanotubes that can be easily operated at room temperature but has a high detection limit. ${ }^{28}$ In recent years, considerable advances have been achieved in optical or photoelectric DCM sensors due to the superiority of optical signals in fast response, low loss, and flexible optical spectra modulation. Han et al. have introduced a DCM detector based on near-infrared absorptive sensing and obtained high resolution, ${ }^{29}$ while the optical sensor based on fluorescence quenching behavior in Cd metal-organic framework is found to be highly efficient. ${ }^{30}$ However, some problems, such as photobleaching under the excitation of ultraviolet light and the anti-interference problem, should be resolved for these optical sensors to exhibit high performance. ${ }^{29,30}$ Lopes et al. reported a bioluminescent (lux) bacterial bioreporter for the detection of DCM and achieved a detection limit of $1.0 \mathrm{ppm}$ under exposure to vapor phase and $0.1 \mathrm{ppm}$ under exposure to liquid phase with response times of $2.3 \mathrm{~h}$ and $1.3 \mathrm{~h}$, respectively. ${ }^{31}$

Here, we report a nanoporous fluorescent sensor based on UCNPs with high sensitivity and low detection limit along with the advantages of low energy consumption, stable photochemical properties, and sensing at room temperature. The sensor based on $\mathrm{NaGdF}_{4}: \mathrm{Yb}, \mathrm{Er} @ \mathrm{NaYF}_{4}: \mathrm{Yb}$ active-core@active-shell UCNPs (ACAS-AAO) exhibit higher sensitivity and response 
rate for the detection of trace amount of DCM than the one based on UCNPs with inert shells. This is due to the following facts. First, with the increasing concentration of DCM, activecore@active-shell UCNPs shows higher intensity than core UCNPs with/without inert shells. ${ }^{32}$ Second, ACAS-AAO shows an exponential dependence of the fluorescent intensity on the concentration of DCM, while UCNPs with/without inert shells show a linear dependence of the fluorescent intensity on the concentration of DCM. In addition, AAO templates can improve the local molecule exchange of DCM through capillarity action such that the supported UCNPs can rapidly and efficiently capture DCM molecules. Based on this ACAS-AAO sensor, a detection limit of $2.91 \mathrm{ppm}$ can be achieved in the detection of DCM. The involved response mechanism was ascribed to reduced surface fluorescence quenching and scattering of upconversion nanocrystals by DCM.

\section{Experimental}

\subsection{Chemical and reagents}

Rare earth oxides $\left(\mathrm{Gd}_{2} \mathrm{O}_{3}, \mathrm{Yb}_{2} \mathrm{O}_{3}, \mathrm{Er}_{2} \mathrm{O}_{3}, \mathrm{Y}_{2} \mathrm{O}_{3}\right)$, oleic acid (OA), octadecene (ODE, 90\%), $\mathrm{NaOH}$ (98\%), $\mathrm{NH}_{4} \mathrm{~F}$ (98\%), cyclohexane, hydrochloric acid, methanol, acetic acid, and dichloromethane, were purchased from afar (Tianjin) chemical effective company and used without further purification. AAO templates were purchased from Shenzhen Topology Film Technology.

\subsection{Synthesis of UCNPs}

UCNPs with/without shells were synthesized by the solvothermal method in the solvent system of OA/ODE with slight modification, which is described in detail in the ESI. $\uparrow^{33}$

\subsection{Gas sensing measurement}

The gas sensing performance of the nanoporous fluorescent sensor was investigated at room temperature $\left(30^{\circ} \mathrm{C}, 303 \mathrm{~K}\right)$ with a relative humidity of $40 \%$. The above sensor was transferred into a glass container sealed with a rubber stopper. Then, DCM was introduced into the container by a syringe needle, while the flux was controlled by a flow counter. The whole device was placed in a spectrometer for real-time indication of the concentration of DCM gas. The response (\%) was defined as $\left(I_{\mathrm{D}}\right.$ $\left.-I_{0}\right) / I_{0}$, in which $I_{0}$ is the upconversion emission intensity without dichloromethane, and $I_{\mathrm{D}}$ is the upconversion emission intensity with dichloromethane.

Note that UCNPs synthesized by the solvothermal method in OA/ODE system still had a thin coating of OA after washing with ethanol and distilled water. The nanoporous fluorescent sensor based on OA-coated UCNPs was hydrophobic, and its fluorescent intensity was dependent on the concentration of DCM but

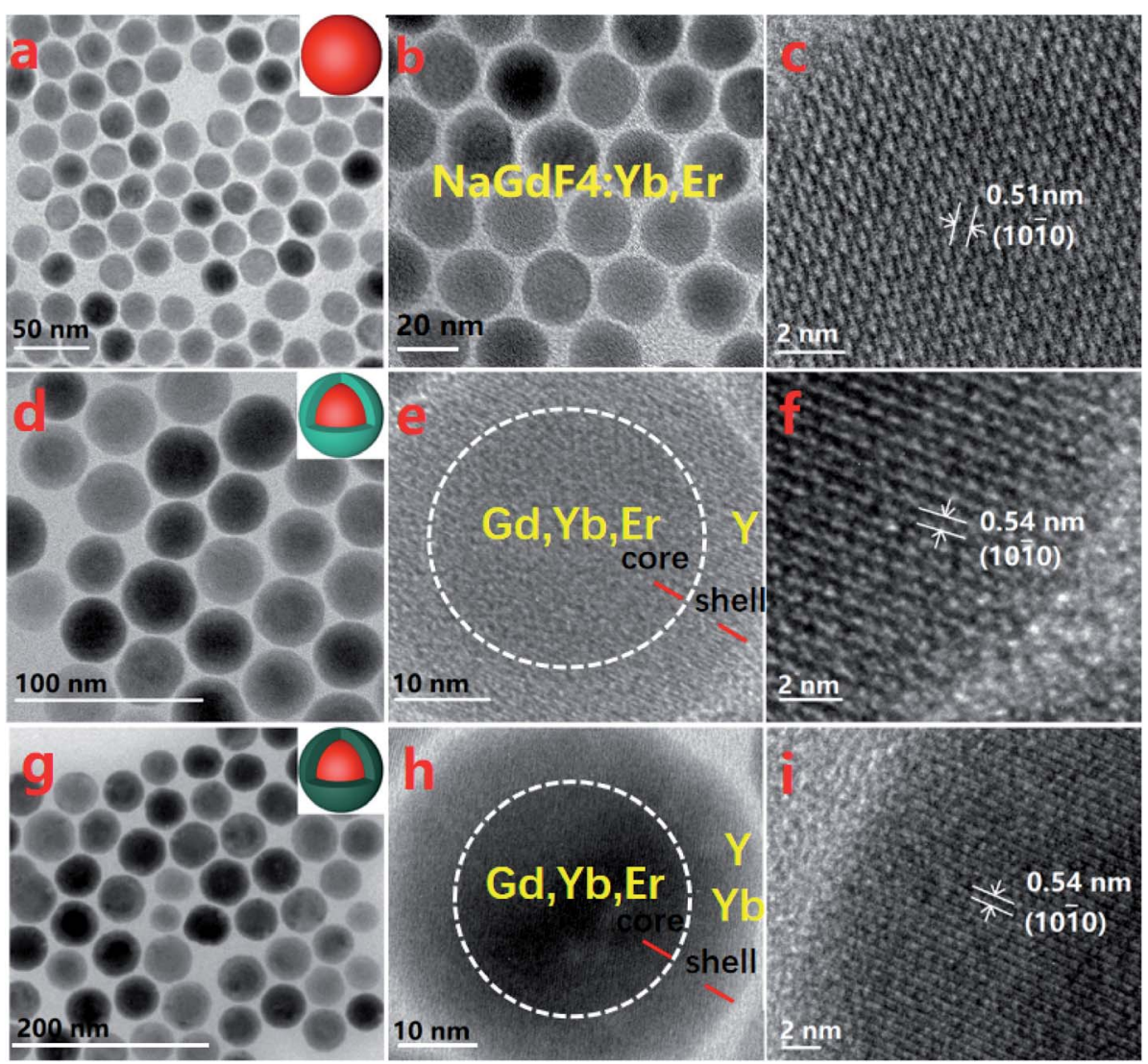

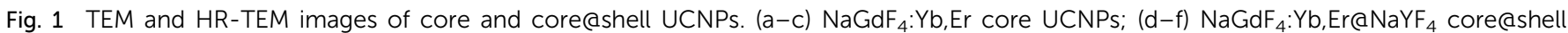
UCNPs; (g-i) NaGdF 4 :Yb, EraNaYF 4 :Yb coreashell UCNPs. 
independent of the relative humidity in the range of $0 \%-70 \%$. Furthermore, the sensor based on active core@active shell UCNPs has good selectivity and reversibility, with the data being presented in the ESI (Fig. S6 and S7). $\dagger$

\subsection{The characterization of UCNPs and AAO}

The size and shape of the lanthanide-doped core and core@shell UCNPs were determined by a transmission electron microscope (JEM-2100F operating at the voltage of $200 \mathrm{kV}$ ). The structure of the anodized aluminum template with and without UCNPs was characterized by a scanning electron microscope (Field emission JSM-6700F). The composite structure AAO@core@shell can be excited by $980 \mathrm{~nm}$ infrared laser and, upon excitation, it emits a green light at $540 \mathrm{~nm}$. The fluorescence spectra were obtained using the Hitachi-F2700 spectrometer.

\section{Result and discussion}

3.1. The morphology, structure, and fluorescence spectra of core and core@shell UCNPs

The morphology and particle size of $\mathrm{NaGdF}_{4}: 18 \% \mathrm{Yb}^{3+} / 2 \% \mathrm{Er}^{3+}$ nanoparticles with and without shells were determined from TEM images shown in Fig. 1. From Fig. 1a-c, it is clear that $\mathrm{NaGdF}_{4}: 18 \% \mathrm{Yb}^{3+} / 2 \% \mathrm{Er}^{3+}$ nanoparticles possess spherical shape, hexagonal phase (Fig. S1 $\dagger$ ), a uniform particle size of $25 \mathrm{~nm}$, and exposed $\mathrm{NaGdF}_{4}$ crystal planes (111) with an interplanar spacing of $0.51 \mathrm{~nm}$. After epitaxial growth with a $\mathrm{NaYF}_{4}$ inert shell of $7.6 \pm 0.5 \mathrm{~nm}$ (Fig. 1d-f), the spherical shapes and uniform particle size were retained; however, $\mathrm{NaYF}_{4}$ crystal planes (111) were exposed with an interplanar spacing of $0.54 \mathrm{~nm} . \mathrm{NaGdF}_{4}: \mathrm{Yb}, \mathrm{Er} @ \mathrm{NaYF}_{4}: \mathrm{Yb}$ ACAS nanoparticles, shown in Fig. 1g-i, exhibit spherical shapes and a shell thickness of 8.9 $\pm 1.0 \mathrm{~nm}$, but $\mathrm{NaYF}_{4}: 5 \% \mathrm{Yb}$ crystal planes (111) were exposed with an interplanar spacing of $0.54 \mathrm{~nm}$. All these core-only and core@shell UCNPs can be dispersed in cyclohexane. ${ }^{34}$ These UCNPs can emit strong green light centered at $540 \mathrm{~nm}$ under the excitation of $980 \mathrm{~nm}$ near-infrared light (Fig. 2a). Clearly, the core@shell nanoparticles exhibit a much higher fluorescent intensity than bare core nanoparticles, ${ }^{35}$ while the nanoparticles with active shells possess the highest fluorescent intensity. In addition, these nanoparticles emit red light centered at $655 \mathrm{~nm}$ and violet light centered at $410 \mathrm{~nm}$ of much lower intensities. This indicates that the emitter $\mathrm{Er}^{3+}$ ion had a dominant $4 \mathrm{f}_{n^{-}}$electronic population on the level of ${ }^{4} S_{3 / 2}$ through the nonradiation relaxation of ${ }^{4} \mathrm{~F}_{7 / 2} \rightarrow{ }^{4} \mathrm{~S}_{3 / 2}$ that further goes down to the ground state for emitting green light. ${ }^{36}$ The photoluminescence mechanisms of these nanoparticles can be deeply revealed by studying the dependency of the luminescent intensity on the excitation power. According to Auzel's theory, the luminescent intensity $(I)$ is proportional to excitation power $(P): I \approx P^{n}$, where $n$ is the number of infrared excitation photons for producing a visible emission photon. The dependence of luminescent intensity on the excitation power is shown in Fig. 2b-d for $\mathrm{NaGdF}_{4}: \mathrm{Yb}, \mathrm{Er}, \mathrm{NaGdF}_{4}: \mathrm{Yb}, \mathrm{Er} @ \mathrm{NaYF}_{4}$, and $\mathrm{NaGdF}_{4}: \mathrm{Yb}, \mathrm{Er} @ \mathrm{NaYF}_{4}: \mathrm{Yb}$, respectively, under a weak excitation power density from 0.30 to $0.42 \mathrm{~W} \mathrm{~mm}^{-2}$ with an interval of $0.02 \mathrm{~W} \mathrm{~mm}^{-2}$

It can be determined from the slope value of Fig. $2 b-d$ that absorption of $\sim 3$ infrared photons of $980 \mathrm{~nm}$ was required to produce a green photon of $540 \mathrm{~nm}$, which is different from the commonly reported conditions, in which two infrared photons are absorbed by UCNPs to generate a green photon of $540 \mathrm{~nm}$.
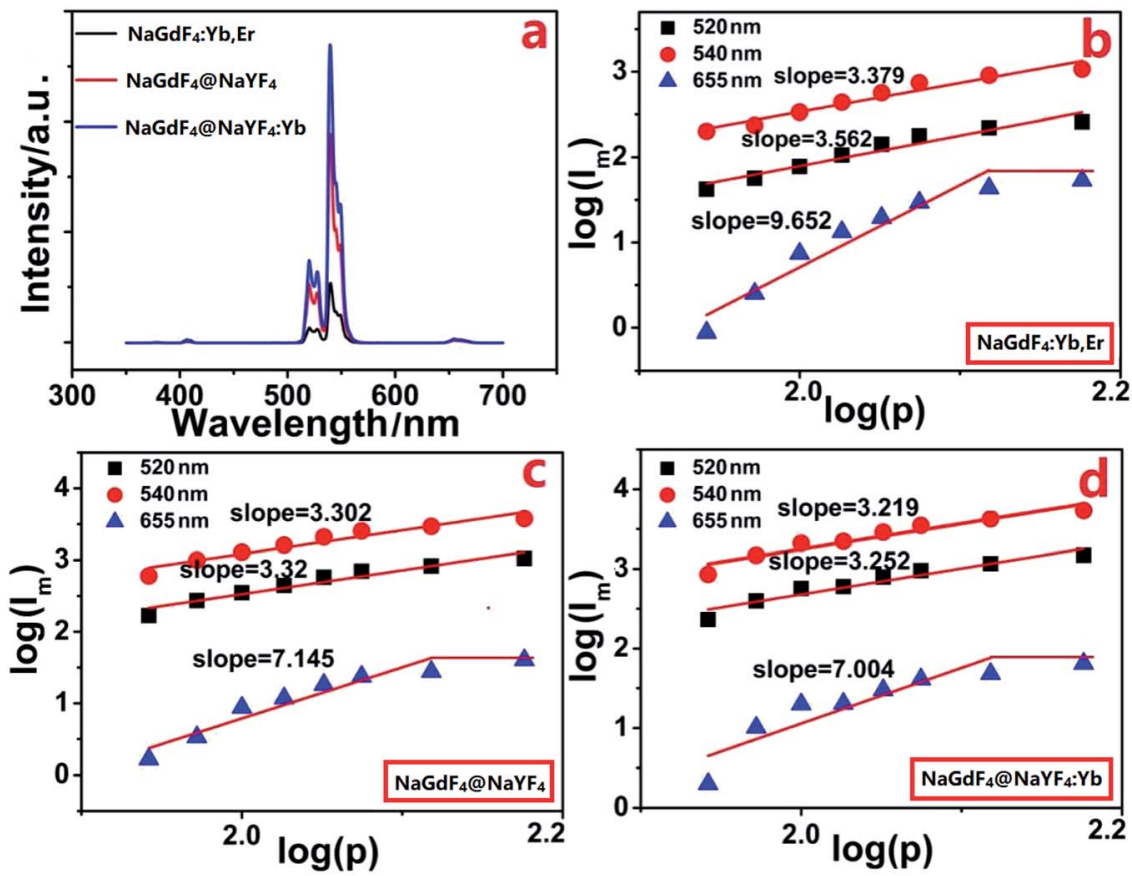

Fig. 2 (a) The fluorescence spectra of core and coreashell UCNPs. Dependence of fluorescence intensity $\left(I_{\mathrm{m}}\right)$ on the excitation power density

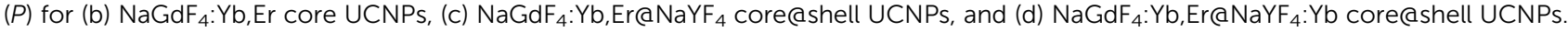




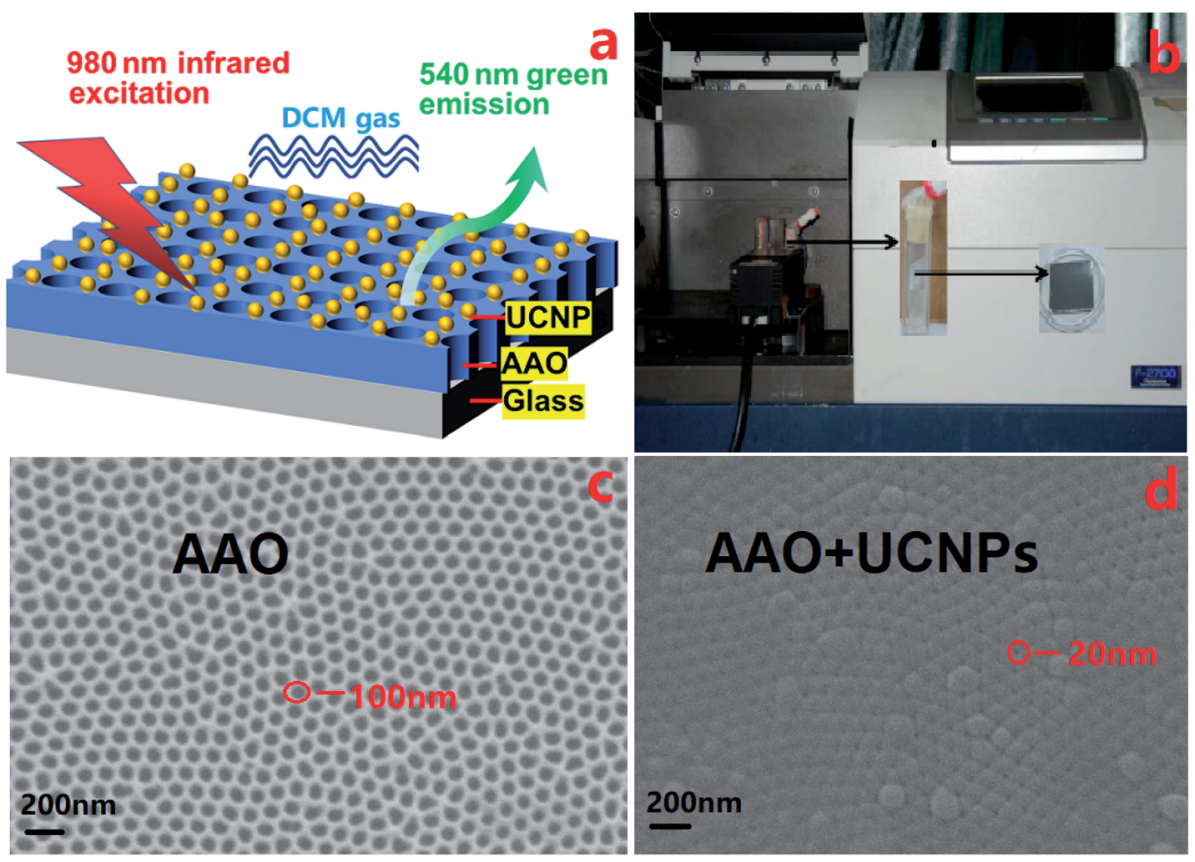

Fig. 3 (a) A model diagram of (ACAS-AAO) nanoporous sensor. (b) The real sensor ACAS-AAO is placed in a sealed container with DCM gas which is located in a spectrometer (Hitachi F-2700). SEM images of AAO templates without UCNPs (c) and with UCNPs (d).

This indicates that the energy exchange among electrons was almost negligible in photon upconversion processes under weak excitation. Thus, the slope value indicates a weak energy exchange among electrons of the emitter $\mathrm{Er}^{3+}$ ions that is beyond the relationship between the emission intensity and excitation power described by Auzel's equation. In this

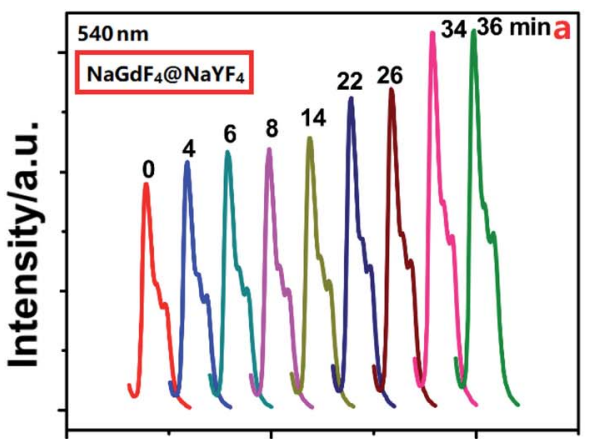

Time/min

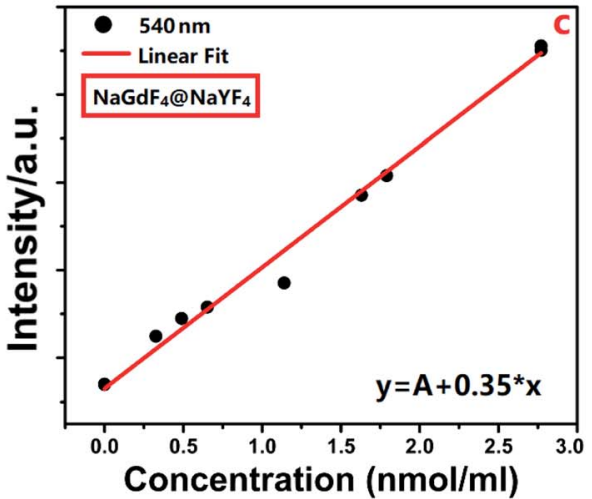

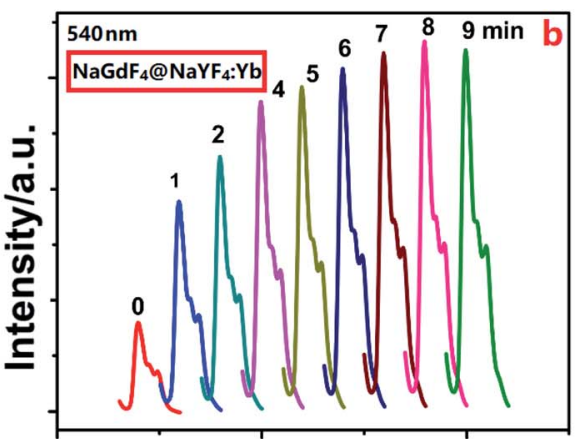

Time / min

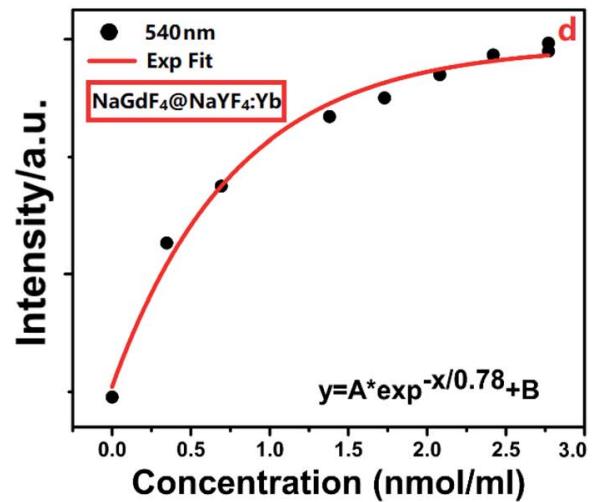

Fig. 4 The detection of DCM gas based on porous AAO supported UCNPs sensor. Dependence of fluorescence intensity (540 nm) on the introduction time of DCM gas into the sealed container based on (a) the sensor with NaGdF 4 :Yb,EraNaYF $F_{4}$ UCNPs and (b) the sensor with $\mathrm{NaGdF}_{4}: \mathrm{Yb}_{2} \mathrm{EraNaYF}_{4}: \mathrm{Yb}_{\mathrm{N}} \mathrm{UCNPs}$. Dependence of upconversion emission intensity $(540 \mathrm{~nm}$ ) on the concentration of DCM gas based on (c) the sensor with $\mathrm{NaGdF}_{4}: \mathrm{Yb}$, EraNaYF 4 UCNPs and (d) the sensor with $\mathrm{NaGdF}_{4}: \mathrm{Yb}$, Er@ NaYF $4: \mathrm{Yb}$ UCNPs. 
condition, we could actually observe the simplest upconversion process of a single $\mathrm{Er}^{3+}$ ion with negligible energy transfer between $\mathrm{Er}^{3+}$ ions. Furthermore, it is observed from Fig. 2b$\mathrm{d}$ that the slope value of both green $(540 \mathrm{~nm}$ and $520 \mathrm{~nm})$ and red $(655 \mathrm{~nm})$ emissions are inversely proportional to the photoluminescence efficiency.

$\mathrm{NaGdF}_{4}: \mathrm{Yb}, \mathrm{Er} @ \mathrm{NaYF}_{4}: \mathrm{Yb}$ active core@active shell nanoparticles show the highest photoluminescence efficiency (Fig. 2a) $)^{32}$ but exhibit the lowest slope value (Fig. 2d). In other words, $\mathrm{NaGdF}_{4}: \mathrm{Yb}, \mathrm{Er} @ \mathrm{NaYF}_{4}: \mathrm{Yb}$ active core@active shell UCNPs had an obviously higher upconversion efficiency for single $\mathrm{Er}^{3+}$ ion than $\mathrm{NaGdF}_{4}: \mathrm{Yb}, \mathrm{Er}$ and $\mathrm{NaGdF}_{4}: \mathrm{Yb}, \mathrm{Er} @ \mathrm{NaYF}_{4}{ }^{-}$ UCNPs. Hence, it is noteworthy that upconversion nanoprobes usually exhibit high sensitivity when excited by a relatively low power density because the molecules to be tested breaks down the independent upconversion process of a single emitter. However, the strong energy exchange between emitters is commonly generated by excitation with high power density because for breaking the energy exchange between emitters usually requires additional energy or stronger external impact.

As a result, it is important to reveal the upconversion characteristics of upconversion nanoprobes under a low power density to determine their potential sensitivity as fluorescent probes. Undoubtedly, from Fig. 2, it is clear that $\mathrm{NaGdF}_{4}$ :$\mathrm{Yb}, \mathrm{Er} @ \mathrm{NaYF}_{4}: \mathrm{Yb}$ active core@active shell nanoparticles should possess the highest sensitivity as optical probes under excitation with low power density. However, the practical effect will be presented in the detection of DCM (Fig. 4).

\subsection{The nanoporous structure of DCM gas sensor}

To detect DCM, a sensor was designed and fabricated based on UCNPs. UCNPs were first deposited on AAO templates supported by glass slides to form a thin film-like gas sensor (Fig. 3a). Subsequently, the film sensor was placed in a glass container sealed with a rubber stopper. Then, DCM gas was introduced into the container by a syringe needle while controlling the flux by a flow counter. The whole device was placed in a spectrometer for real-time indication of the concentration of DCM gas (Fig. 3b). In addition, the structure of AAO templates with/without UCNPs is presented in Fig. 3c and $\mathrm{d}$, respectively. The figure reveals that the porous AAO template had an average pore diameter of $100 \mathrm{~nm}$ and an average wall thickness of $20 \mathrm{~nm}$, while the AAO template with UCNPs had an average pore diameter of $19 \mathrm{~nm}$ and an average wall thickness of $101 \mathrm{~nm}$. This indicates that UCNPs were successfully coated on AAO templates to generate a porous film with the same pore sites as in the AAO template but with much smaller pore size.

\subsection{Sensing behaviors of DCM gas sensor based on UCNPs and AAO template}

Based on the above sensor, the concentration of DCM gas can be determined through real-time monitoring of the green fluorescence spectra $(540 \mathrm{~nm})$ under the excitation of infrared light of $980 \mathrm{~nm}$. Fig. $4 \mathrm{a}$ and $\mathrm{b}$ show that the emission intensity of UCNPs increases on extending the import time of DCM gas. This enhancement was ascribed to the lowered surface scat-

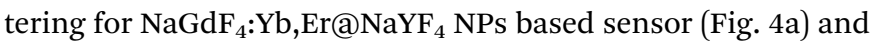
lowered surface quenching and scattering for $\mathrm{NaGdF}_{4}$ :$\mathrm{Yb}$,Er@NaYF 4 :Yb NPs based sensor (Fig. 4b). Thus, the active shell with the sensitizer $\mathrm{Yb}^{3+}$ ions had a strong influence on the luminescence of the core. However, the active shell contacts closely with the DCM molecules. Consequently, the active shell actually plays a role of an energy bridge between the fluorescent probe (emission core) and the DCM molecules to be tested such that the $\mathrm{NaGdF}_{4}: \mathrm{Yb}, \mathrm{Er} @ \mathrm{NaYF}_{4}: \mathrm{Yb}$ NPs-based sensor exhibits

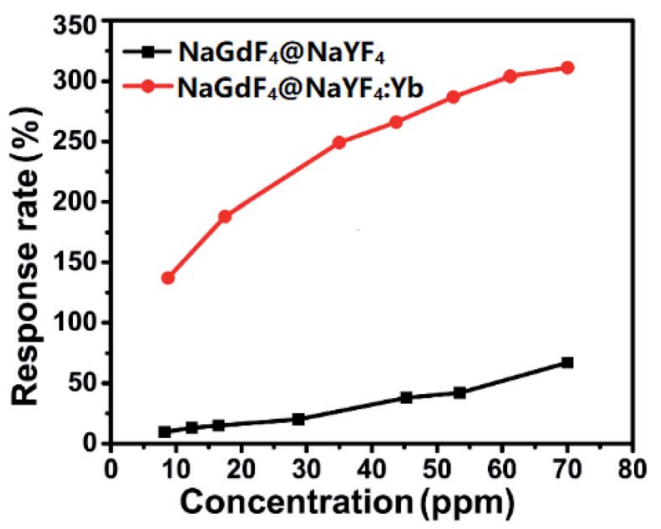

Fig. 6 The response rate of nanoporous sensors to the varying concentration of dichloromethane gas.
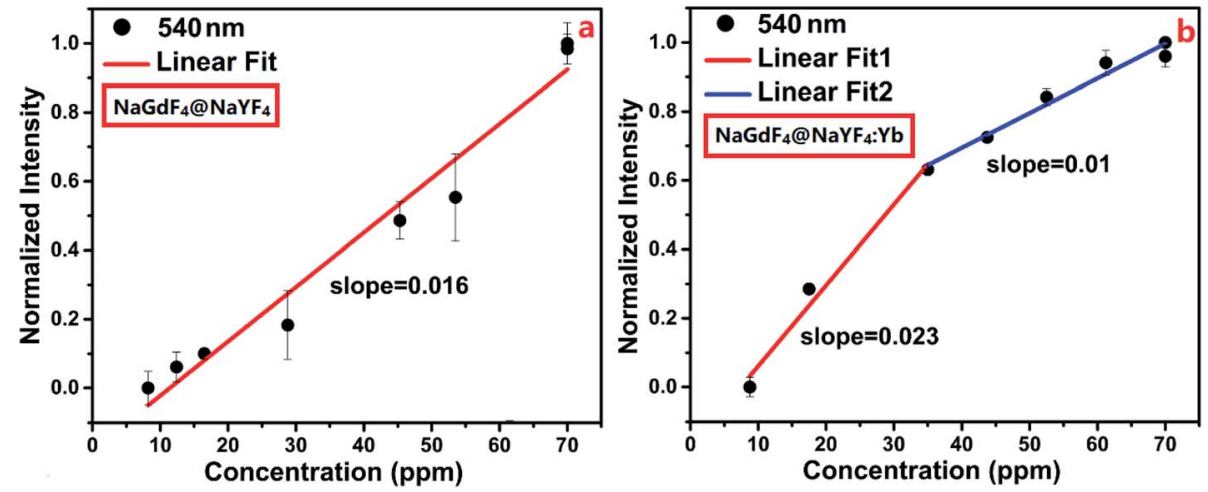

Fig. 5 The linear fitting curve of the emission intensity vs. the concentration of DCM gas based on the nanoporous sensors. 
Table 1 The comparison of different gas sensor for $\mathrm{DCM}^{a}$

\begin{tabular}{|c|c|c|c|c|c|}
\hline & & $0.1-0.8$ & 0.1 & & 22 and 23 \\
\hline $\mathrm{TiO}_{2}$ & 250 & $10-50$ & None & Resistance & 24 \\
\hline Polymer (PECH) & 20 & 2000-18000 & 294 & Frequency & 26 \\
\hline \multirow[t]{2}{*}{ Methylobacterium } & 20 & $1-100$ & 1 & Bioluminescent & 31 \\
\hline & 280 & $0.1-100$ & 0.1 & & \\
\hline UCNPs C/S (Y, Yb) & RT & $2.91-70$ & 2.91 & Spectrum & This work \\
\hline $\mathrm{C} / \mathrm{S}(\mathbf{Y})$ & RT & $4.91-70$ & 4.91 & & \\
\hline
\end{tabular}

a much higher response rate than the $\mathrm{NaGdF}_{4}: \mathrm{Yb}, \mathrm{Er} @ \mathrm{NaYF}_{4}$ NPs-based sensor. The dependence of emission intensity on the concentration of DCM gas is shown in Fig. 4c and d. A linear relationship with a coefficient of 0.35 was observed for

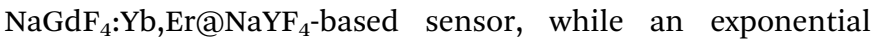
relationship with a coefficient of 0.78 was observed for $\mathrm{NaGdF}_{4}: \mathrm{Yb}, \mathrm{Er} @ \mathrm{NaYF}_{4}: \mathrm{Yb}$.

The linear dependence of normalized emission intensities on the concentration of DCM gas is shown in Fig. 5. It is clear that a linear relationship with a coefficient of 0.016 was observed for a $\mathrm{NaGdF}_{4}: \mathrm{Yb}, \mathrm{Er} @ \mathrm{NaYF}_{4}$-based sensor, and a detection limit of $4.91 \mathrm{ppm}$ was determined. The linear relationship with a coefficient of 0.023 and 0.01 was observed for a NaGdF $4: \mathrm{Yb}, \mathrm{Er} @ \mathrm{NaYF}_{4}: \mathrm{Yb}$-based sensor at the low concentration and a relatively higher concentration of dichloromethane, respectively, while a detection limit of $2.91 \mathrm{ppm}$ was determined. The dependence of fluorescence intensity $(540 \mathrm{~nm})$ on the concentration of DCM gas was measured and is shown, for the glass slide supported UCNPs sensor (without AAO template), in Fig. S3 and S4 of the ESI. $\dagger$ It is quite clear that AAO templates play the role of efficient absorbers for stably capturing DCM molecules around UCNPs. ${ }^{37}$ For the condition without AAO templates (Fig. S3 and S4 in the ESI $\dagger$ ), DCM molecules flow through UCNPS randomly such that UCNPs cannot sense the linear increase of the concentration of DCM gas. As a result, a non-monotonous dependence of emission intensity on the concentration of DCM gas was observed (Fig. S4 in the ESI $\dagger$ ).

The response curves of the sensor based on UCNPs with/ without active shells are presented in Fig. 6. From the figure, it is quite clear that a $\mathrm{NaGdF}_{4}: \mathrm{Yb}, \mathrm{Er} @ \mathrm{NaYF}_{4}: \mathrm{Yb}$-based sensor presents a much higher response to the concentration variation of DCM gas, while the sensor based on UCNPs with active shells shows a maximum response of $308 \%$, which was 4.5 times greater than the sensor based on UCNPs with inert shells. In comparison with previously reported sensors for detecting DCM molecules (Table 1), these nanoporous sensors based on the AAO template supported upconversion nanocrystals exhibit a relatively lower detection limit to DCM at room temperature.

\section{Conclusion}

A highly sensitive nanoporous fluorescent sensor based on UCNPs was demonstrated for the detection of DCM. UCNPs were deposited on AAO templates supported by glass slides to form a thin film-like gas sensor in which UCNPs with active shells exhibited intense background-free fluorescence and simultaneously high optical sensitivity, while anodic alumina oxide template supplies a porous substrate for UCNPs to increase the absorption capacity for molecules to be tested. Based on this sensor, a detection limit of 2.91 ppm was obtained for DCM, and the involved response mechanism was ascribed to the lowered su 1rface fluorescence quenching and scattering of upconversion nanocrystals by DCM.

\section{Conflicts of interest}

There are no conflicts to declare.

\section{Acknowledgements}

This work was funded by the National Natural Science Foundations of China (Grant No. 61675067 and 61674056) and the Scientific Research Fund of Hunan Province Education Department (Grant No. 16C0627).

\section{References}

1 Y. X. Liu, D. S. Wang, L. L. Li, Q. Peng and Y. D. Li, Inorg. Chem., 2014, 53, 3257-3259.

2 F. Wang, D. Banerjee, Y. Liu, X. Chen and X. Liu, Analyst, 2010, 135, 1839-1854.

3 W. Zheng, P. Huang, D. T. Tu, E. Ma, H. M. Zhu and X. Y. Chen, Chem. Soc. Rev., 2015, 44, 1379-1415.

4 K. S. Zou, G. Z. Dong, J. C. Liu, B. X. Xu and D. P. Wang, J. Mater. Sci. Technol., 2019, 35, 483-490.

5 S. Fischer, J. C. Goldschmidt, P. Loper, G. H. Bauer, R. Bruggemann, K. Kramer and S. W. Glunz, J. Appl. Phys., 2010, 108, 044912. 
6 L. Y. Wang and Y. D. Li, Chem. Commun., 2006, 2557.

7 R. Deng, X. J. Xie, M. Vendrell, Y. T. Chang and X. Liu, J. Am. Chem. Soc., 2011, 133, 20168-20171.

8 P. Huang, W. Zheng, S. Y. Zhou, D. T. Tu, Z. Chen, H. M. Zhu, R. F. Li, E. Ma, M. D. Huang and X. Y. Chen, Angew. Chem., Int. Ed., 2014, 53, 1252-1257.

9 J. Peng, W. Xu, C. L. Teoh, S. Han, B. Kim, A. Samanta, J. C. Er, L. Wang, X. G. Liu and Y. T. Chang, J. Am. Chem. Soc., 2015, 137, 2336-2342.

10 C. X. Li, J. L. Liu, S. Alonso, F. Y. Li and Y. Zhang, Nanoscale, 2012, 4, 65-71.

11 X. H. Li, Y. Q. Wu, Y. Liu, X. M. Zou, L. M. Yao, F. Y. Li and W. Feng, Nanoscale, 2014, 6, 1020-1028.

12 Z. H. Chen, X. F. Wu, S. G. Hu, P. Hu, H. Yan, Z. J. Tang and Y. X. Liu, J. Mater. Chem. C, 2015, 3, 153-161.

13 H. S. Mader and O. S. Wolfbeis, Anal. Chem., 2010, 82, 50025004.

14 N. Wang, Z. Li, W. Liu, T. Deng, J. Yang, R. Yang and J. Li, ACS Appl. Mater. Interfaces, 2019, 11, 26684-26689.

15 N. Wang, X. Yu, K. Zhang, C. A. Mirkin and J. Li, J. Am. Chem. Soc., 2017, 139, 12354-12357.

16 F. Wang, C. L. Zhang, X. T. Qu, S. S. Cheng and Y. Z. Xian, Biosens. Bioelectron., 2019, 126, 96-101.

17 P. M. Schlosser, A. S. Bale, C. F. Gibbons, A. Wilkins and G. S. Cooper, Environ. Health Perspect., 2015, 123, 114-119.

18 A. S. Bale, S. Barone, C. S. Scott and G. S. Cooper, Toxicol. Appl. Pharmacol., 2011, 255, 113-126.

19 G. V. Alexeeff and W. W. Kilgore, J. Toxicol. Environ. Health, Part A, 1983, 11, 569-581.

20 C. Wen, A. Bassig, R. Vermeulen, W. J. Seow, W. Hu and M. P. Purdue, Ann. Epidemiol., 2014, 24, 688.

21 D. S. Skrabalak and J. G. Babish, Regul. Toxicol. Pharmacol., 1983, 3, 139-143.

22 W. S. Lee, S. C. Lee, S. J. Lee, D. D. Lee, J. S. Huh, H. K. Jun and J. C Kim, Sens. Actuators, B, 2005, 108, 148-153.

23 S. C. Lee, H. Y. Choi, S. J. Lee, W. S. Lee, J. S. Huh, D. D. Lee and J. C. Kim, Sens. Actuators, B, 2009, 138, 446-452.
24 H. P. Young, H. K. Song, C. S. Lee and J. G. Jee, J. Ind. Eng. Chem., 2008, 14, 818-823.

25 N. J. Choi, Y. S. Lee, J. H. Kwak, J. S. Park, K. B. Park, K. S. Shin, H. D. Park, J. C. kim, J. S. Huh and D. D. Lee, Sens. Actuators, B, 2005, 108, 177-183.

26 F. D. Pietrantonio, M. Benetti, D. Cannata, E. Verona, A. Palla-Papavlu, V. Dinca, M. Dinescu, T. Mattle and T. Lippert, Sens. Actuators, B, 2012, 174, 158-167.

27 D. Matatagui, M. J. Fernandez, J. Fontecha, J. P. Santos, I. Gracia, C. Cane and M. C. Horrillo, Sens. Actuators, B, 2012, 175, 173-178.

28 W. Muangrat, V. Yordsri, R. Maolanon, S. Pratontep, S. Porntheeraphat and W. Wongwiriyapan, Diamond Relat. Mater., 2016, 65, 183-190.

29 J. H. Han and S. M. Yoon, IEEE J. Sel. Top. Quantum Electron., 2012, 18, 1547-1552.

30 Y. Xia, K. Cao, M. Han and Y. Feng, Inorg. Chem. Commun., 2015, 76-78.

31 N. Lopes, S. A. Hawkins, P. Jegier, F. Menn, G. S. Sayler and S. Ripp, J. Ind. Microbiol. Biotechnol., 2012, 39, 45-53.

32 V. F. Vetrone, R. Naccache, V. Mahalingam, C. G. Morgan, J. A. Capobianco and J. Advanced, Funct. Mater., 2009, 19, 2924-2929.

33 Y. X. Liu, J. Vanacken, X. M. Chen, J. B. Han, Z. Q. Zhong, Z. C. Xia, B. R. Chen, H. Wu, Z. Jin, J. Y. Ge, J. W. Huang, L. Meng, X. F. Duan, Y. Huang, Q. Peng, V. Moshchalkov and Y. D. Li, Adv. Mater., 2019, 31, 1806341.

34 T. C. Cao, T. S. Yang, Y. Gao, Y. Yang, H. Hu and F. Y. Li, Chem. Commun., 2010, 392-394.

35 F. Wang, R. R. Deng, J. Wang, Q. X. Wang, Y. Han, H. M. Zhu, X. Y. Chen and X. G. Liu, Nat. Mater., 2011, 10, 968-973.

36 Y. Wang, L. P. Tu, J. W. Zhao, Y. J. Sun, X. G. Kong and H. Zhang, J. Phys. Chem. C, 2009, 113, 7164-7169.

37 A. Santos, T. Kumeria and D. Losic, Trends Anal. Chem., 2013, 44, 25-38. 